\title{
Aging, cognitive decline, apolipoprotein E and docosahexaenoic acid metabolism
}

\author{
Mélanie Plourde , $^{1, *}$ \\ ${ }^{1}$ Department of medicine, Université de Sherbrooke, Research Center on Aging, Sherbrooke, 1036 Belvédère Sud Sherbrooke, J1H 4C4 \\ Quebec, Canada \\ ${ }^{2}$ Institute of Nutrition and Functional Foods, Laval University, Québec, QC, Canada
}

Received 20 March 2018 - Accepted 17 May 2018

\begin{abstract}
In Canada, 17 millions of adults between 30-64 years old could benefit from a prevention strategy to lower the risk of Alzheimer's disease (AD). My group is working on a population that is particularly at risk of $\mathrm{AD}$, the carriers of an epsilon 4 allele of apolipoprotein $\mathrm{E}(E 4)$, a genetic risk. Around $20 \%$ of the population in industrial countries have this genetic risk but not all carriers will develop AD, suggesting that environmental factors modulate the clinical manifestation and risk of AD in the carriers. My group has discovered that the metabolism of docosahexaenoic acid (DHA) is disrupted during aging and in E4 carriers, a finding replicated in homozygous mice knocked-in for human E4 allele ( $h A P O E 4)$. We recently showed that a diet containing DHA prevented behavioral deficits in $h A P O E 4$ mice. Another group reported in $E 4$ carriers that the ratio of arachidonic acid (ARA): DHA is disrupted in the plasma and constitute a preclinical marker of mild cognitive impairment/AD in E4 carriers. Using our kinetics approaches with uniformly labelled carbon 13 fatty acids, we showed that the kinetics of ${ }^{13} \mathrm{C}$-DHA is modified by age and $E 4$ carriage. The kinetics of ${ }^{13} \mathrm{C}$-arachidonic acid was however not modified by age conversely to that of ${ }^{13} \mathrm{C}$-eicosapentaenoic acid (EPA). We also reported that the synthesis of ${ }^{13} \mathrm{C}$-DHA from ${ }^{13} \mathrm{C}$-EPA started $2 \mathrm{~h}$ after the tracer intake in older adults conversely to $7 \mathrm{~d}$ in young men. Whether old men needs in DHA is higher or whether their ability to use it is lower remains to be established. These differences in the DHA and EPA metabolism seems, however related to physiological modifications occurring during aging and in $E 4$ carriers and obscure the relationship between plasma DHA and EPA levels, dietary fatty fish intake and cognitive status.
\end{abstract}

Keywords: docosahexaenoic acid / arachidonic acid / eicosapentaenoic acid / aging / cognitive decline / apolipoprotein E / kinetics

Résumé - Vieillissement, déclin cognitif, apolipoprotéine $\mathrm{E}$ et métabolisme de l'acide docosahexaénoöque. Au Canada, 17 millions d'adultes âgés entre 30-64 ans pourraient bénéficier d'une intervention en prévention pour diminuer leur risque de développer la maladie d'Alzheimer (MA). L'un des groupes les plus à risque de développer la $\mathrm{MA}$, les porteurs de l'allèle epsilon 4 de l'apolipoprotéine $\mathrm{E}(E 4)$, est au centre des recherches menées par mon groupe. Environ $20 \%$ de la population des pays industrialisés sont porteurs d'E4 mais ce ne sont pas tous les porteurs qui développeront la MA, ce qui suggère que des facteurs environnementaux puissent moduler l'expression clinique et le risque de la MA chez les porteurs. Nous avons découvert que le métabolisme de l'acide docosahexaénö̈que (DHA) est débalancé pendant le vieillissement et chez les porteurs de l'E4. Ces découvertes ont été répliquées dans un modèle de souris transgénique dont l'apolipoprotein de souris a été remplacé par de l'E4 humaine (hAPOE4). Nous avons récemment montré qu'une diète riche en DHA prévenait les déficits comportementaux chez la souris hAPOE4. Un autre groupe a montré que le ratio acide arachidonique (ARA) : DHA était débalancé dans le plasma des humains $E 4$ et que ce marqueur constituait un marqueur pré-clinique de déclin cognitif léger/MA chez les $E 4$. Avec notre approche de cinétique des acides gras uniformément marqués au carbone 13, nous avons montré que les cinétiques du ${ }^{13} \mathrm{C}$-DHA et du ${ }^{13} \mathrm{C}$-eicosapentaénoïque (EPA) étaient modifiées avec l'âge et chez les porteurs de l'E4. Cependant, la cinétique du ${ }^{13} \mathrm{C}$-ARA n'était pas modifiée avec l'âge. Nous

*Correspondence: Melanie.Plourde2@usherbrooke.ca 
avons également rapporté que, chez les personnes âgées, la synthèse du ${ }^{13} \mathrm{C}$-DHA débutait $2 \mathrm{~h}$ après la consommation du ${ }^{13} \mathrm{C}$-EPA tandis que cette production débutait seulement 7 jours après sa consommation chez les participants jeunes. Il est donc important de comprendre si les besoins en DHA des personnes âgées sont plus importants que ceux des jeunes, d'où sa synthèse précoce à partir de l'EPA ou si l'habilité des participants âgés à utiliser le DHA est plus basse, ce qui expliquerait son accumulation dans le plasma. Ces différences dans le métabolisme de l'EPA et du DHA semblent reliées à des modifications physiologiques qui ont lieu durant le vieillissement et chez les porteurs de l'E4, ce qui pourrait obscurcir la relation entre leurs niveaux dans le sang, la consommation de poisson gras et le statut de la cognition.

Mots clés : acide docosahexaénoïque / acide arachidonique / acide eicosapentaénoïque / vieillissement / déclin cognitif / apolipoprotéine $\mathrm{E} /$ cinétique

\section{Introduction}

In Canada, 5.5 million (16\% of Canadians) of adults are $>65$ years old and projections suggest this number will be around $20 \%$ of Canadians by 2024 . In France in $2005,16 \%$ of French were $>65$ years old representing around 10.7 million citizen. Projection scenario points towards $>25 \%$ of French being $>65$ in 2030 in this represents roughly 17 million people. With higher life expectancy, older adults will live longer with a chronic disease. Among chronic diseases, Alzheimer disease (AD) is the one disease older adults is the most afraid of because the disease lead to memory decline and subsequently to lower ability to take care of themselves. The Alzheimer Society Canada reports that the current number of Canadians living with a cognitive disease is 564000 and that there are each year 25000 new cases. In the next 15 years, it is anticipated that the number of Canadian affected by a cognitive disease will double. The annual cost to Canadian to take care of someone with a cognitive disease is $>\$ 10$ billion CAN annually. The scenario is similar in France and in other industrial countries.

$\mathrm{AD}$ is characterized by memory decline affecting daily life and limiting the patient daily ability to dress and wash themselves as well as being able to cook and eat alone. The disease also affects language, speech and time and space orientation and increase anxiety. Physiopathology of the disease is characterized by b-amyloid plaques and neurofibrillary tangles of tau protein. Together, these two components contribute to neurodegeneration. Many pharmaceutical treatments have been tried over the years but none have succeeded to alt the progression of the disease or even treat the symptoms of the disease. Therefore, one of the best strategies remains prevention of the disease onset.

\section{Evidence of effective prevention strategies}

Among the different prevention strategies for AD, diet has been a lot investigated. In 2009, we have published a literature review suggesting that consumption of $\geq 2$ fish servings/weeks reduces risk of AD (Cunnane et al., 2009), Since the publication of this paper, many other prospective and randomized control trials (RCT) have been published and have reported mixed results. Most of the RCT did not found a causative effect on the consumption of fish oil. In 2013, Dacks et al. published a review of the literature showing that in participants without cognitive decline, taking an omega-3 fatty acid supplement did not gain benefit on cognition (Dacks et al., 2013). In contrast, participants with subjective cognitive complaints could experience cognitive benefits from taking omega-3 fatty acid supplements (Dacks et al., 2013). A recent study has supplemented for 2 years patients with precursor signs of Alzheimer's disease. The active ingredient was composed of omega-3 fatty acids, uridine, choline, phosphates and $\mathrm{B}$ vitamins but this supplementation had no effect on cognitive scores compared to the placebo (Soininen et al., 2017). Thus, there is currently no consensus on the effectiveness of a nutritional strategy to prevent or limit the progression of cognitive decline. In the absence of an effective therapy for the treatment of Alzheimer's disease, there is a need to clarify whether a nutritional intervention strategy alone or in combination with other treatments are effective.

The new trend in the field of Alzheimer's disease prevention is multimodal interventions. The Finnish Geriatric Intervention Study to Prevent Impairment and Disability (FINGER) is a multimodal intervention that consists of a dietary modification to reach the targets of nutritional recommendations of Finland, aerobic exercise 2-5 times a week and muscle training 1-3 times a week, cognitive training with group sessions to explain agerelated cognition changes, and computer-based exercises to perform at home. This intervention also focuses on the management of cardiovascular risks for those aged between 60 and 77 years (Ngandu et al., 2015). After 2 years of intervention, the executive functions and the execution speed were significantly higher in the group that received the intervention than in the control group, which supports that the intervention prevented cognitive decline (Ngandu et al., 2015). Another ongoing study in France is the Multidomain Alzheimer Preventive Trial (MAPT study) which includes supplementation with omega-3 fatty acids, as well as nutritional counselling, physical exercise and cognitive stimulation. This procedure was performed for 3 years in frail patients aged 70 and over. In this study, multi-domain intervention and supplementation with omega-3 fatty acids, alone or in combination, did not prevent cognitive decline (Andrieu et al., 2017). Thus, multimodal approaches should be targeted to younger people without apparent risk factors for AD.

\section{Dysregulation of the metabolism of long chain fatty acid during aging}

Unlike saturated and mono-unsaturated fatty acids, synthesis of eicosapentaenoic acid (EPA, 20:5 omega-3) and docosahexaenoic acid (DHA, 22:6 omega-3) from its omega-3 PUFA precursor, alpha-linolenic acid (18:3 omega-3), is extremely limited in humans (Plourde and Cunnane, 2007). Thus, it is recommended that DHA be obtained from dietary 
sources such as fish and seafood. Intake of EPA and DHA from fish normally correlates positively with the concentrations of EPA and DHA in plasma (Vidgren et al., 1997). However, recent data suggest that EPA levels are approximately twice higher in plasma lipids of the elderly as compared to young individuals, suggesting that potential alterations in EPA incorporation and utilization occur during aging (Fortier et al., 2010). Similar results were obtained with a DHAenriched supplement where the increase of DHA in plasma total lipids was $42 \%$ higher in the elderly compared to the young [Reviewed by (Fortier et al., 2010)]. In another study, dietary intake of $90 \mathrm{mg} / \mathrm{d}$ of DHA for 15 months was not sufficient to increase DHA in plasma total lipids of both a young elderly (aged 60-80 years old) and an old elderly (over 80 years old) group, but $180 \mathrm{mg} / \mathrm{d}$ of EPA increased the plasma EPA concentration by 53-109\% (Rodriguez-Palmero et al., 1997). Moreover, a persistent significant positive correlation between EPA or DHA and age even after correction for fish intake was reported (de Groot et al., 2009), but age apparently contributed from only $2-4 \%$ to the amount of explained variance in EPA and DHA incorporation into plasma PL (de Groot et al., 2009). Whether this percentage is clinically and physiologically relevant is unknown, but it gives important indications that incorporation of EPA and DHA is altered during aging and as a consequence, it has the potential to alter the utilization and uptake of these fatty acids by tissues and organs which might enhance the risk of chronic diseases such as cardiovascular diseases and cognitive declines. Indeed, there are evidences supporting that higher omega-3 PUFA levels in the erythrocyte is associated with better cognitive functions later life (Schaefer et al., 2006) and cardiac benefits (Harris et al., 2008). Therefore, better knowledge of the biology of aging and more specifically with regards to omega-3 PUFA metabolism would help define better nutritional strategies for preventing diseases in the elderly.

To do so, there is a need to use labelled fatty acids. These fatty acids can be labeled on one or more carbons with deuterium or the fatty acid can be uniformly labeled with carbon 13 instead of carbon 12 . The latter also allows to evaluate fatty acid betaoxidation since when it is beta-oxidized, it produces carbon 13 $\mathrm{CO}_{2}\left({ }^{13} \mathrm{C}-\mathrm{CO}_{2}\right)$. The first studies using uniformly labelled carbon 13-labeled fatty acids were performed by the group of Michel Lagarde (Lyon, France) when they investigated the metabolism of ${ }^{13} \mathrm{C}$-DHA in young humans (Brossard et al., 1996; Lemaitre-Delaunay et al., 1999). After receiving an oral dose of $250-280 \mathrm{mg}$ in ${ }^{13} \mathrm{C}$-DHA, ${ }^{13} \mathrm{C}$ enrichment peaked $2 \mathrm{~h}$ post-dose in plasma TG when the tracer was given in the TG form, but at $6 \mathrm{~h}$ post-dose when the tracer was esterified to phosphatidylcholine (Brossard et al., 1996; Lemaitre-Delaunay et al., 1999). Brossard et al. have reported a 1.4\% apparent retroconversion of ${ }^{13} \mathrm{C}$-DHA to ${ }^{13} \mathrm{C}$-docosapentaenoate (22:5 omega3 ) and ${ }^{13} \mathrm{C}$-EPA $3 \mathrm{~d}$ after giving the tracer (Brossard et al., 1996). These results showed the feasibility of tracing DHA metabolism in humans. However, neither the impact of aging on ${ }^{13} \mathrm{C}$-DHA metabolism nor its beta-oxidation was investigated. We traced ${ }^{13} \mathrm{C}$-DHA metabolism in six young (mean -27 years old) and six old (mean -77 years old) participants. We found that, $4 \mathrm{~h}$ postdose, in the elderly, ${ }^{13} \mathrm{C}$-DHA was 4 times higher in plasma TG and free fatty acids and beta-oxidation was 1.9 times higher compared to the young (Plourde et al., 2011). Apparent retroconversion of ${ }^{13} \mathrm{C}$-DHA to other ${ }^{13} \mathrm{C}$-omega-3 PUFA was
2.1 times higher $24 \mathrm{~h}$ and $7 \mathrm{~d}$ after tracer intake compared to the young (Plourde et al., 2011). This result can be explained by the elderly having both higher postprandial productions of very lowdensity lipoproteins and free fatty acid response. Hence, because DHA seems to remain transiently for longer periods of time in the blood of the old $v s$. the young, it may thus indicate a lower efficiency to remove DHA from the blood in the old vs. the young, resulting in lower incorporation of DHA in the membrane of cells that serve to initiate signaling pathways (Bazan, 2007). Hence, by using ${ }^{13} \mathrm{C}$-DHA, we were able to show postprandial alterations in the management of DHA in the old compared to the young and increased the knowledge on the biology of aging. This lower efficiency potentially results in lower incorporation of DHA in the membranes of different cells including immune cells (Rees et al., 2006; Vandal et al., 2008; Plourde, 2009; Fortier et al., 2010).

Our most recent work with tracers between old and young men was conducted with ${ }^{13} \mathrm{C}$-eicosapentaenoic acid $\left({ }^{13} \mathrm{C}\right.$-EPA) or arachidonic acid $\left({ }^{13} \mathrm{C}-\mathrm{ARA}\right)$, two key fatty acids that are precursors of anti- and pro-inflammatory cytokines, respectively. Surprisingly, the kinetics of ${ }^{13} \mathrm{C}$-EPA and ${ }^{13} \mathrm{C}$-ARA was similar between young and old men (Leveille et al., 2017). However, one intriguing result we obtained was that in old men, synthesis of DHA from EPA started $2 \mathrm{~h}$ after tracer intake whereas it was delayed to $1 \mathrm{~d}$ in young men (Leveille et al., 2017). This result suggests that old adults might need more DHA than what was actually provided in their diet compared to the young adults. However, newly synthesized DHA accumulates in the plasma of old men for $7 \mathrm{~d}$ and this might be because it remains for a longer period in the plasma as suggested by our previous study with ${ }^{13} \mathrm{C}$-DHA (Plourde et al., 2011). Therefore, there might be a defect of cells such as immune cells in old adults to uptake EPA and DHA resulting in lower anti-inflammatory responses to insults. In the old men, ${ }^{13} \mathrm{C}$-EPA whole-body half-life was $\sim 14$ days and in the younger group it was $\sim 21$ days (Leveille et al., 2017). This result indicates that turn-over of EPA is $\sim 7$ days faster in older adults compared to younger adults. This is an intriguing result since epidemiological studies and the results from a previous study from our group (Plourde et al., 2009a) support that old adults have twice as much plasma EPA, hence, one would anticipate a lower whole-body turnover in old vs young adults. Altogether, our group provided evidence that:

- the level of plasma DHA is slightly modified by age but the metabolism of DHA is highly modified by age: why the two are disconnected needs further investigation;

- the level of EPA in the plasma of old adults is twice that of the young but the metabolism (kinetics) is only slightly modified;

- the level of ARA in the plasma is $25 \%$ higher in old vs young adults but the kinetics is not modified by age;

- are these plasma levels and kinetics imbalances obscure the potential relationship between plasma n-3 FA and cognition?

\section{One genetic risk factor of $A D$ also affecting DHA metabolism}

Apolipoprotein E (ApoE) is a protein-regulating lipid transport and metabolism (Mahley, 1988). The brain has its 
own pool of apoE (Pitas et al., 1987) that plays critical roles in lipid transport to neurons. The $A P O E$ gene has three isoforms: epsilon $2(E 2)$, epsilon $3(E 3)$ and epsilon $4(E 4)$. In humans, homozygotes for $E 2$ genotype suffer from hypertriglyceridemia and this feature has also been reported in apoE targeted replacement mice with the human E2 ( $h A P O E 2$ ) (Lane and Farlow, 2005; Sharman et al., 2010). In humans, E4 is the most important genetic risk of AD (Coon et al., 2007, Bertram and Tanzi, 2009) and hAPOE4 mice have memory decline similar to that reported in humans (Bour et al., 2008; Siegel et al., 2010). Therefore, this mouse model seems to be excellent to study $A P O E$ genotype imbalances on the metabolism of lipids.

Approximately, 20\% of Canadians carry the E4 allele which almost doubles their risk of late-onset $\mathrm{AD}$ whereas in USA, the frequency of the $E 4$ allele is around 15\% (Bullido et al., 1998). AD risk is closely linked to changes in lipid metabolism and plasma DHA levels were inversely associated to the brain Ab load (Yassine et al., 2016). Some suggest that the $E 4$ allele induce a decrease in levels of apoE protein in the brain (i.e. loss of function) (Poirier, 2008) whereas other series of data support a gain-of-negative function in neurite sprouting, or any E4-specific activity in the brain (Teter, 2004). One consensus however, is related to the key role of apoE protein in the transport and delivery of lipids within the brain (Poirier, 2008; Poirier et al., 2014). Carrying an E4 allele is associated with several hallmarks of AD such as Ab peptide deposition, oxidative stress, inflammation, lipid homeostasis deregulation, loss of synaptic plasticity and cholinergic dysfunction (Mahley et al., 2009; Kim et al., 2014; Poirier et al., 2014; Salem et al., 2015).

The story about carrying the E4 allele and DHA metabolism imbalance emerge when a paper was published in 2005 by Huang et al. (2005). This group showed that benefits of fatty fish on dementia risks were stronger for those without the E4 allele. Our group proposed that this lack of benefit was potentially because of DHA imbalance. We then tested whether $E 4$ carriers were responders to an EPA+DHA supplement. This was performed as a pilot study in a secondary analysis of a study originally designed by Prof Vohl (Paradis et al., 2005). We compared the fatty acid profile of the different lipid pools in the plasma: phospholipids, free fatty acids, triglycerides (TG) and cholesteryl esters. Before the $\mathrm{EPA}+\mathrm{DHA}$ supplementation, the level of DHA in plasma TG was 55\% higher in E4 carriers compared to non-carriers (Plourde et al., 2009b). After consuming $1.8 \mathrm{~g} / \mathrm{d}$ EPA $+1.2 \mathrm{~g} / \mathrm{d}$ DHA for 6 weeks, DHA increased by $65 \%$ in plasma TG of $E 4$ carriers while the increase was by $180 \%$ in the non-carriers (Plourde et al., 2009b). We then conducted a study using ${ }^{13} \mathrm{C}$ DHA in E4 carriers and non-carriers and we found that its kinetics was imbalanced in E4 carriers in the postprandial phase (Chouinard-Watkins et al., 2013). Ones could question how important these imbalances play to better health. It is important to know that the plasma DHA pool is critical to bring DHA to the brain and it is dynamic, constantly exchanging FA with organs and tissues. Under conditions of chronic low dietary n-3 FA, the liver usually upregulates its ability to synthesize DHA and presumably receives alpha-linolenic acid (ALA) from the adipose tissue. Hence, it is suggested that there is an adipose-liver-brain FA axis (Bazinet and Laye, 2014). In mice, we recently published that under an omega-3 FA deficient diet, hAPOE4 mice had similar plasma DHA levels to that of $h A P O E 3$ mice, but the liver and the adipose tissue DHA levels were $\sim 46 \%$ lower in $h A P O E 4$ mice than in $h A P O E 3$ mice fed the same diet (Nock et al., 2017). Therefore, to maintain plasma DHA levels, hAPOE4 mice had to pull DHA from, or prevent DHA getting into the liver and the adipose tissue. The reasons for maintaining plasma DHA levels might be to support brain DHA levels as we have shown that consequences on brain FA profile of $h A P O E 4$ mice consuming a deprived diet in omega-3 FA are only expressed in the long term since the ALA and DHA reservoir gets empty (Conway et al., 2014; Vandal et al., 2014). This condition accentuates their vulnerability to omega-3 FA deficiency. The ALA: linoleic acid (LA) ratio, an indicator of the capacity to convert ALA to DHA was $\sim 80 \%$ lower in the liver of $h A P O E 4$ compared to $h A P O E 3$ mice. We recently reviewed the neurological consequences of omega-3 FA dietary deficiency that includes a 3-fold reduction in the capillaries of the adult rat brain, smaller neuron size and lower neuronal membrane fluidity (Nock et al., 2017). Hence, hAPOE4 might be more vulnerable to omega-3 FA deficiency and this process might be accentuated during aging due to a loss of delta- 6 desaturase activity as expressed by the ALA: LA ratio (Horrobin, 1981).

Another important point with regards to brain DHA uptake is that, in mice, it was shown to be not saturable at concentrations up to 100 microM suggesting that it crosses the blood-brain barrier (BBB) by simple diffusion. We showed in $h A P O E 4$ mice, that brain ${ }^{14} \mathrm{C}$-DHA uptake was $24 \%$ lower in $h A P O E 4$ than $h A P O E 2$ mice but cortex DHA levels were lower in 13 month-old hAPOE4 mice only (Vandal et al., 2014). Abdullah et al. suggested that Mfsd2a level, a brain transport protein of lyso-phosphatidylcholine-DHA (lyso-PCDHA), was lower in E4 carriers and in hAPOE4 mice compared to that of E3 carriers and $h A P O E 3$ mice (Abdullah et al., 2016). Lower Mfsd2a levels correlated with lower DHA and a higher ARA levels in brain membrane (Abdullah et al., 2016). Her group also showed that $E 4$ carriers converting to mild cognitive impairment (MCI)/AD had higher ARA: DHA ratio in $\mathrm{PC}$ and lyso-PC compared to cognitively normal E4 carriers and $E 4$ non-carriers (Abdullah et al., 2017). Aldullah et al. also reported a similar higher ARA: DHA ratio in $\mathrm{PC}$ and lyso-PC in hAPOE4 mice compared to $h A P O E 3$ mice supporting that this mice model also have an imbalance in DHA and ARA compartment packaging (Abdullah et al., 2017). In 35 year-old humans, a positron emission tomography study with $\left[1-{ }^{11} \mathrm{C}\right]-\mathrm{DHA}$ reported however, that the mean global gray matter incorporation of DHA in the brain of $E 4$ carriers was $16 \%$ higher than in non-carriers (Yassine et al., 2017). This higher uptake was particularly emphasized in the entorhinal region, an area affected early in AD pathogenesis and it was suggested by the authors it might represent a compensatory mechanism in younger $E 4$ carriers to cope with increased brain DHA loss thus to maintain brain DHA levels (Yassine et al., 2017). Therefore, at younger ages, E4 carriers might require more DHA than non-carriers to support brain DHA turnover and prevent accumulation of $\mathrm{Ab}$ peptide since it was shown that higher plasma DHA levels were inversely associated to the brain Ab load (Yassine et al., 2016). However, Abdullah et al. showed that a fish oil supplement modulate the ARA: DHA ratio in carriers and non-carriers of $E 4$ suggesting that E4 carrier could somehow benefit from a fish oil supplement in rebalancing the ARA: DHA ratio but this may 
be conditional to higher doses and longer duration than what has currently been published yet on the topic. This hypothesis is supported by our recent study in $h A P O E 4$ mice fed a control or a diet containing DHA where the DHA diet in hAPOE4 prevented spatial memory deficits as compared to the control diet (Chouinard-Watkins et al., 2017). However, the mechanism explaining this preventive effect remains unknown (Chouinard-Watkins et al., 2017). In another study, the authors reported that the metabolic and cognitive deficits in $h A P O E 4$ mice fed a high fat diet inducing insulin resistance were rescued by switching to a low fat diet for 1 month suggesting a functional role of dietary FA in $h A P O E 4$ mice on top of a structural role (Johnson et al., 2017). Therefore, it seems that hAPOE4 mice could benefit from a higher consumption in DHA (Chouinard-Watkins et al., 2017) but this remains to be established in humans. A recent paper from the FINGER study, a multidomain intervention of 2 years, support this hypothesis since they concluded that healthy lifestyle changes may sustain cognition in older at-risk E4 carriers (Solomon et al., 2018). Although it do not related specifically to omega-3 fatty acid metabolism/supplementation, it indicates that AD risk can be modulated in E4 carriers and non-carriers and thus, this strategy should be encourage and developed better to be implemented in our communities.

\section{Conclusion}

There is currently no cure nor treatment to AD. Prevention strategies are urgently needed since the aging population will be one of the most significant forces shaping our economy and society in the next $20-30$ years. Moreover, there is $15-20 \%$ of the population carrying the $E 4$ genetic risk that increases the risk of AD. However, not all E4 carriers develop AD suggesting that lifestyle such as nutrition can modulate AD expression. We have identified that DHA metabolism is imbalanced during aging and in E4 carriers and these imbalances could limit DHA delivery to replenish brain DHA levels during aging and in E4 carriers. Our work contributes to understand how to limit these defects and help to decrease the risk of $\mathrm{AD}$ in $E 4$ carriers. A reduction of even $10 \%$ in the prevalence of $\mathrm{AD}$ would markedly diminish the impact of this disease on society and on life quality of the aging population.

\section{References}

Abdullah L, Evans J, Shackleton B, et al. 2016. APOE4 genotype dependant deficits in DHA containing phospholipids and DHA transporters in the cerebrovasculature of Alzheimer's disease patients. Alzheimer's Association International Conference, Toronto.

Abdullah L, Evans JE, Emmerich T, et al. 2017. APOE epsilon4 specific imbalance of arachidonic acid and docosahexaenoic acid in serum phospholipids identifies individuals with preclinical mild cognitive impairment/Alzheimer's disease. Aging (Albany NY) 9: 964-985.

Andrieu S, Guyonnet S, Coley N, et al. 2017. Effect of long-term omega 3 polyunsaturated fatty acid supplementation with or without multidomain intervention on cognitive function in elderly adults with memory complaints (MAPT): a randomised, placebocontrolled trial. Lancet Neurol 16: 377-389.

Bazan NG. 2007. Omega-3 fatty acids, pro-inflammatory signaling and neuroprotection. Curr Opin Clin Nutr Metab Care 10: 136-141.

Bazinet RP, Laye S. 2014. Polyunsaturated fatty acids and their metabolites in brain function and disease. Nat Rev Neurosci 15: 771-785.

Bertram L, Tanzi RE. 2009. Genome-wide association studies in Alzheimer's disease. Hum Mol Genet 18: R137-R145.

Bour A, Grootendorst J, Vogel E, et al. 2008. Middle-aged human apoE4 targeted-replacement mice show retention deficits on a wide range of spatial memory tasks. Behav Brain Res 193: 174-182.

Brossard N, Croset M, Pachiaudi C, Riou JP, Tayot JL, Lagarde M. 1996. Retroconversion and metabolism of $[13 \mathrm{C}] 22: 6 n-3$ in humans and rats after intake of a single dose of [13C]22:6n-3triacylglycerols. Am J Clin Nutr 64: 577-586.

Bullido MJ, Artiga MJ, Recuero M, et al. 1998. A polymorphism in the regulatory region of APOE associated with risk for Alzheimer's dementia. Nat Genet 18: 69-71.

Chouinard-Watkins R, Rioux-Perreault C, Fortier M, et al. 2013. Disturbance in uniformly 13C-labelled DHA metabolism in elderly human subjects carrying the apoE epsilon4 allele. Br J Nutr 110: 1751-1759.

Chouinard-Watkins R, Vandal M, Leveille P, Pincon A, Calon F, Plourde M. 2017. Docosahexaenoic acid prevents cognitive deficits in human apolipoprotein E epsilon 4-targeted replacement mice. Neurobiol Aging 57: 28-35.

Conway V, Larouche A, Alata W, Vandal M, Calon F, Plourde M. 2014. Apolipoprotein $\mathrm{E}$ isoforms disrupt long-chain fatty acid distribution in the plasma, the liver and the adipose tissue of mice. Prostaglandins Leukot Essent Fatty Acids 91: 261-267.

Coon KD, Myers AJ, Craig DW, et al. 2007. A high-density wholegenome association study reveals that APOE is the major susceptibility gene for sporadic late-onset Alzheimer's disease. $J$ Clin Psychiatry 68: 613-618.

Cunnane SC, Plourde M, Pifferi F, Begin M, Feart C, BarbergerGateau P. 2009. Fish, docosahexaenoic acid and Alzheimer's disease. Prog Lipid Res 48: 239-256.

Dacks PA, Shineman DW, Fillit HM. 2013. Current evidence for the clinical use of long-chain polyunsaturated n-3 fatty acids to prevent age-related cognitive decline and Alzheimer's disease. J Nutr Health Aging 17: 240-251.

de Groot RH, van Boxtel MP, Schiepers OJ, Hornstra G, Jolles J. 2009. Age dependence of plasma phospholipid fatty acid levels: potential role of linoleic acid in the age-associated increase in docosahexaenoic acid and eicosapentaenoic acid concentrations. Br J Nutr: 1-7.

Fortier M, Tremblay-Mercier J, Plourde M, et al. 2010. Higher plasma n-3 fatty acid status in the moderately healthy elderly in southern Quebec: higher fish intake or aging-related change in n-3 fatty acid metabolism? Prostaglandins Leukot Essent Fatty Acids 82: $277-280$.

Harris WS, Miller M, Tighe AP, Davidson MH, Schaefer EJ. 2008. Omega-3 fatty acids and coronary heart disease risk: clinical and mechanistic perspectives. Atherosclerosis 197: 12-24.

Horrobin DF. 1981. Loss of delta-6-desaturase activity as a key factor in aging. Med Hypotheses 7: 1211-1220.

Huang TL, Zandi PP, Tucker KL, et al. 2005. Benefits of fatty fish on dementia risk are stronger for those without APOE epsilon4. Neurology 65: 1409-1414. 
Johnson LA, Torres ER, Impey S, Stevens JF, Raber J. 2017. Apolipoprotein E4 and insulin resistance interact to impair cognition and alter the epigenome and metabolome. Sci Rep 7: 43701.

Kim J, Yoon H, Basak J. 2014. Apolipoprotein E in synaptic plasticity and Alzheimer's disease: potential cellular and molecular mechanisms. Mol Cells.

Lane RM, Farlow MR. 2005. Lipid homeostasis and apolipoprotein E in the development and progression of Alzheimer's disease. $J$ Lipid Res 46: 949-968.

Lemaitre-Delaunay D, Pachiaudi C, Laville M, Pousin J, Armstrong M, Lagarde M. 1999. Blood compartmental metabolism of docosahexaenoic acid (DHA) in humans after ingestion of a single dose of $\left[\left({ }^{13}\right) \mathrm{C}\right] \mathrm{DHA}$ in phosphatidylcholine. J Lipid Res 40: $1867-1874$

Leveille P, Chouinard-Watkins R, Windust A, et al. 2017. Metabolism of uniformly labeled 13C-eicosapentaenoic acid and 13C-arachidonic acid in young and old men. Am J Clin Nutr.

Mahley RW. 1988. Apolipoprotein E: cholesterol transport protein with expanding role in cell biology. Science 240: 622-630.

Mahley RW, Weisgraber KH, Huang Y. 2009. Apolipoprotein E: structure determines function, from atherosclerosis to Alzheimer's disease to AIDS. J Lipid Res 50(Suppl.): S183-S188.

Ngandu T, Lehtisalo J, Solomon A, et al. 2015. A 2-year multidomain intervention of diet, exercise, cognitive training, and vascular risk monitoring versus control to prevent cognitive decline in at-risk elderly people (FINGER): a randomised controlled trial. Lancet 385: 2255-2263.

Nock TG, Chouinard-Watkins R, Plourde M. 2017. Carriers of an apolipoprotein $\mathrm{E}$ epsilon 4 allele are more vulnerable to a dietary deficiency in omega-3 fatty acids and cognitive decline. Biochim Biophys Acta 1862: 1068-1078.

Paradis AM, Fontaine-Bisson B, Bosse Y, et al. 2005. The peroxisome proliferator-activated receptor alpha Leu162Val polymorphism influences the metabolic response to a dietary intervention altering fatty acid proportions in healthy men. $\mathrm{Am} \mathrm{J}$ Clin Nutr 81: 523-530.

Pitas RE, Boyles JK, Lee SH, Foss D, Mahley RW. 1987. Astrocytes synthesize apolipoprotein E and metabolize apolipoprotein Econtaining lipoproteins. Biochim Biophys Acta 917: 148-161.

Plourde M. 2009. Does altered omega-3 fatty acid metabolism contributing to cognitive aging? In: Gariépy Q, Ménard R, eds. Cognitive aging: causes, processes and effects. Hauppauge, NY: Nova Science Publishers.

Plourde M, Cunnane SC. 2007. Extremely limited synthesis of long chain polyunsaturates in adults: implications for their dietary essentiality and use as suppements. Appl Physiol Nutr Metab 32: 619-634.

Plourde M, Tremblay-Mercier J, Fortier M, Pifferi F, Cunnane SC. 2009a. Eicosapentaenoic acid decreases postprandial betahydroxybutyrate and free fatty acid responses in healthy young and elderly. Nutrition 25: 289-294.

Plourde M, Vohl MC, Vandal M, Couture P, Lemieux S, Cunnane SC. 2009b. Plasma n-3 fatty acid response to an n-3 fatty acid supplement is modulated by apoE epsilon4 but not by the common PPAR-alpha L162V polymorphism in men. Br J Nutr 102: 1121-1124.
Plourde M, Chouinard-Watkins R, Vandal M, et al. 2011. Plasma incorporation, apparent retroconversion and beta-oxidation of 13C-docosahexaenoic acid in the elderly. Nutr Metabol 8: 5.

Poirier J. 2008. Apolipoprotein E represents a potent gene-based therapeutic target for the treatment of sporadic Alzheimer's disease. Alzheimers Dement 4: S91-S97.

Poirier J, Miron J, Picard C, et al. 2014. Apolipoprotein E and lipid homeostasis in the etiology and treatment of sporadic Alzheimer's disease. Neurobiol Aging 35(Suppl. 2): S3-S10.

Rees D, Miles EA, Banerjee T, et al. 2006. Dose-related effects of eicosapentaenoic acid on innate immune function in healthy humans: a comparison of young and older men. Am J Clin Nutr 83: 331-342.

Rodriguez-Palmero M, Lopez-Sabater MC, Castellote-Bargallo AI, de la Torre-Boronat MC, Rivero-Urgell M. 1997. Administration of low doses of fish oil derived N-3 fatty acids to elderly subjects. Eur J Clin Nutr 51: 554-560.

Salem N, Jr., Vandal M, Calon F. 2015. The benefit of docosahexaenoic acid for the adult brain in aging and dementia. Prostaglandins Leukot Essent Fatty Acids 92: 15-22.

Schaefer EJ, Bongard V, Beiser AS, et al. 2006. Plasma phosphatidylcholine docosahexaenoic acid content and risk of dementia and Alzheimer disease: the Framingham Heart Study. Arch Neurol 63: 1545-1550.

Sharman MJ, Shui G, Fernandis AZ, 2010 et al. Profiling brain and plasma lipids in human APOE epsilon 2, epsilon 3, and epsilon 4 knock-in mice using electrospray ionization mass spectrometry. $J$ Alzheimers Dis 20: 105-111.

Siegel JA, Haley GE, Raber J. 2010. Apolipoprotein E isoformdependent effects on anxiety and cognition in female TR mice. Neurobiol Aging.

Soininen H, Solomon A, Visser PJ, et al. 2017. 24-month intervention with a specific multinutrient in people with prodromal Alzheimer's disease (LipiDiDiet): a randomised, double-blind, controlled trial. Lancet Neurol 16: 965-975.

Solomon A, Turunen H, Ngandu T, et al. 2018. Effect of the apolipoprotein $\mathrm{E}$ genotype on cognitive change during a multidomain lifestyle intervention: a subgroup analysis of a randomized clinical trial. JAMA Neurol.

Teter B. 2004. ApoE-dependent plasticity in Alzheimer's disease. $J$ Mol Neurosci 23: 167-179.

Vandal M, Alata W, Tremblay C, et al. 2014. Reduction in DHA transport to the brain of mice expressing human APOE4 compared to APOE2. J Neurochem 129: 516-526.

Vandal M, Freemantle E, Tremblay-Mercier J, et al. 2008. Plasma omega-3 fatty acid response to a fish oil supplement in the healthy elderly. Lipids 43: 1085-1089.

Vidgren HM, Agren JJ, Schwab U, Rissanen T, Hanninen O, Uusitupa MI. 1997. Incorporation of n-3 fatty acids into plasma lipid fractions, and erythrocyte membranes and platelets during dietary supplementation with fish, fish oil, and docosahexaenoic acid-rich oil among healthy young men. Lipids 32: 697-705.

Yassine HN, Feng Q, Azizkhanian I, et al. 2016. Association of serum docosahexaenoic acid with cerebral amyloidosis. JAMA Neurol 73: 1208-1216.

Yassine HN, Croteau E, Rawat V, et al. 2017. DHA brain uptake and APOE4 status: a PET study with [1-(11)C]-DHA. Alzheimers Res Ther 9: 23.

Cite this article as: Plourde M. 2018. Aging, cognitive decline, apolipoprotein E and docosahexaenoic acid metabolism. OCL 25(4): D405. 